\title{
Research on the Web Art Design in the Perspective of Aesthetic Yilei Liu ${ }^{1, a}$ Liaoliao $\mathrm{Ji}^{1, \mathrm{~b}}$ \\ ${ }^{1}$ Pingxiang University, Pingxiang, Jiangxi, China, 337055 \\ aemail, bemail,
}

\author{
Keywords: Web Art Design, Perspective, Aesthetic
}

\begin{abstract}
Web design is a comprehensive design, its scope is very broad, good web design in addition to considering the excellence contents but the content should also reasonably effective visual layout. Beauty is the basic elements of any web page and the web page information not only to meet the needs of users, it is more important is to create a pleasant visual environment, so that they have a heart and soul of enjoyment and resonance. Web design should from an aesthetic point of view to explore the initial induction and theory of art and design of this new field.
\end{abstract}

\section{Introduction}

With the development, web design getting closer to an art, not just a technology. Art and design network, the site builder that has focused increasingly, it is the new artistic generation of issues associated with the Internet formed. As a web design across aesthetics, art and design, computer technology, network technology, and many other disciplines, interdisciplinary in ICT matured premise, that is to say after the functionality are met, people tend to aesthetic needs and wants to strengthen the understanding of the information through good creative design. At the same time, changes in design thinking also demand more technical upgrades, technology and aesthetics is in the process of this mutual promotion of the gradual integration as a whole. Human pursuit of beauty is the process of deepening and changing, web design, too, it is not just stack a variety of visual information, but it is important to consider how the viewer can, in the United States pleasant environment more directly and effectively received a variety of information online, and be able to inspire people's participation. This requires us from the aesthetic point of view, the entire site to do a comprehensive framework and overall handle the pages static and dynamic visual elements, beautiful relationship between the kinetic energy and to enhance the Web browsing and interesting. Give users impressed, it is necessary to create a distinctive style. Mobilize all means to fully demonstrate the personality and taste of the website, so that it has a unique style, improve site usage. To strict rules or lively; is elegant or charming alternative bold ,, in shaping style, pay attention to establish the image of the site, color, font unity, improve the layout and the combination of these elements.

\section{The Overview of Art}

Art is a very common spiritual and cultural products, the creator or designer through a variety of means to express the feelings of the heart and creativity in an abstract form, which convey the message you want to express the heart, the infinite and the indefinite It is the development of the arts has exclusive features, along with increasingly higher living standards and aesthetic needs of people watching the degree of artistic beauty are also increasing, and the importance of art in society is also increasing. Art and design in the field of multimedia is a form of artistic means of modern technology under development is the newly developed information technology products, full use of advanced technology and equipment to improve the designs of aesthetic enjoyment, which is the development of multimedia technology in today's society the more important part.

\section{The Overview of Aesthetic}

Beauty is an objective reality of sensory product is the ultimate feeling people get in the practice of 
the process of society, its presence reflects the positive attitude of people in the face of life and joy when the happy mood, different people's understanding of beauty requirements are different, so I generate aesthetic fact is that people in the face of the world, to understand the form of a special understanding of the world, it is a more harmonious relationship status, as long as it refers to humans and nature, as society the forming between an emotional person, and there is no form of figurative relationship utilitarian, aesthetic emotion and the intellect, subjective and objective basis as a unified form, and then respect the truth, and so the development of the United States examined.

\section{Artistic Elements of Web Art Design}

Logo Design of the Site. Logo is the graphic image by simple symbols to convey information plays instructions to identify the role and it must be designed to reflect the information technology, visual, artistic and other visual language features. Its manifestations include design, painting, etc., should be designed to be consistent with the style of the site. Keep the design consistency of style, both visual integrity requirements, but also to ensure that users browse the course will not get lost.

It should also be noted in the design of the following points: First, the rational use of visual space, do not cause congestion, so as not to dazzle the viewer; the second is an international visual language, fashion, easy to be different ethnic groups in various countries people recognized and appreciated; the third is a series of visual design, according to the site's theme, with different backgrounds, colors and dynamic effects, the formation of the series.

Color Design of the Site. "Standard color" refers to the website can reflect and extend the content of the color image, a different color scheme will produce different effects, and may affect the mood of visitors, which utilize color matching techniques should be designed to give the overall sense of unity. The color itself is no meaning, but the color can really affect people's psychology, about people's emotions. The advantage of this is easy to make the page with color consistent, easy to create web stability, harmony and unity, decency effect. The disadvantage is likely to cause the monotony of the page, it is often the use of black and white ash is added to make changes in brightness and color purity or partially added to increase the contrast change.

Using near Hue color. This color easily gives a sweet, elegant and harmonious to enjoy and easy to produce romantic, soft, beautiful feeling. This easy way to shape a distinctive use of color, lively, web effect of exercise, especially for easily embody creative website design should pay attention to one or two colors based, supplemented by other color, otherwise the page will look messy. If the color contrast is very strong, dazzling visual effects appear pages, you should consider using this color transition color to reconcile the relationship, so uncoordinated colors unite. Color transition include the following forms: two color halftone and monochrome mixed with black, white, gray to reconcile, the same color and monochrome mixed reconcile the like.

Font Design of the Site. Standard fonts refers to the used in the page title and font logo on the main menu, usually with the default Times New Roman, for the distinctive and unique style reflects the site, you can choose according to need some special fonts. Text Design should be subordinated to the nature and characteristics of the information required, the style and content to match the characteristics, such as its government pages of text to be solemn and norms, font styling neat and orderly, simple and generous; casual web, typography to light a cheerful, lively fonts, jump sprightly; personal homepage can be combined with personal character, ingenuity, giving a strong unique impression. The design of the text on the page, although the computer provides us with a vast selection of fonts, but on the same page, using several fonts still need careful editing and consideration.

\section{Research on the Web Art Design in the Perspective of Aesthetic}

The Beauty of Web Art Design Features. Although the practical function page with its own functional beauty produced are not necessarily linked, but the utility function has a direct impact on the aesthetic evaluation of its users, the conversion utility may even aesthetic. This function is called the United States the United States. Web design in the pursuit of formal beauty, it must fit the 
needs of the theme, which is the premise of web design. Manifestations and fancy talk too much emphasis on "unique design" and from the content, or just a lack of content and artistic expression, Web design will become hollow and weak. Only two designers organic unity, a deep understanding of the essence of the subject, reintegration own thoughts and feelings, find a perfect form of expression, in order to reflect the specific component and the value of the unique web design. On the other hand, the need to ensure that every element on the page has a presence, not to show off and use redundant technology.

The Beauty of Web Art Design Technology. Simply put, the United States is the modern design technology of how to create a line with the laws of the United States in accordance with people's physical and psychological needs of the beautiful things or products. Interactive Web pages use, integrated multi-dimensional and multi-media, and web design is the perfect embodiment of beauty. Unlike traditional media page of the Department, is that dynamic updates and instant interactive information. Real-time interaction is the main reason Web has become a hot question also must be considered when designing web pages. Traditional media (such as radio, television, newspapers and magazines, etc.) are in a linear fashion to provide information that according to the information provided by the feeling, the experience and pre-established format to spread. In the Web environment, it is no longer a passive recipient of the way traditional media, but in his capacity as an active participant added to the processing and dissemination of information among. Multidimensional stems from the hyperlink, mainly in web design navigation design. Since the emergence of hyperlinks, the organizational structure of the page is more abundant, viewers can freely jump between the various topics, thus breaking the previous people receive information in a linear fashion.

The Beauty in Web Art Design Decoration. Web Design After resolving one of the most technical and functional web page itself reflects the personality of the design step is to decorate. Although Gong says: "Very few hard and see the power and more", pointed out that a good design is when people with functional objects, convenient and pleasant. But the decorative arts as a human society, the most common form of art still have a very important value and significance in the design. Web design decoration should pursue in terms of simplicity, combining function and decoration is an excellent web design works. Chinese people's reading and aesthetic manner and Westerners are quite different, as the Chinese web designers as well as a manifestation of Chinese nation's own aesthetic characteristics of the task, it is not just the effect on the national question, it is a good design work recognized by people or not the premise.

\section{Establish the Page Layout}

Applying the Principle of balance, rhythm, contrast and other rules to a unified layout, adhere to focus, balance and harmony, pay attention to simple structure and interface, reducing the sense of confusion. Page layout with newspapers, magazines and other print media layouts have a lot in common and it occupies an important position in art and design page. The so-called page layout, is in a limited screen space will be viewing multimedia elements organically permutations and combinations, the rational thinking personalized manifested, is a kind of personal style and artistic characteristics of the audio-visual ways to convey it to convey information but also it produces beauty and spiritual senses to enjoy.

During the time of layout, we need to pay attention to the following points: First, prioritize, center highlights. Vision Center is usually a page is at the center or middle of the screen on the side of the site, therefore, some important elements can be arranged in this position, the secondary contents can be arranged in a place other than the visual center; the second is the size of the match, echoed . Longer articles or title not choreographed together, there must be a certain distance, the same arrange short articles, pictures, etc. The same is true, to be staggered, so that the page patchwork can make page rendering rhythm of beauty, but also make page to maintain a balance, avoid the center of gravity: Third illustrations, complement each other. Too many words on the page, it becomes dull and lifeless. Too many pictures will inevitably reduce the amount of information the page. Therefore, close coordination to make the pictures and text, set off each other, both active 
page, and make the rich content of the page.

Use the dynamic design element or that the design elements (such as text, pictures, etc.) dynamic process, saving the limited layout space, but also attracted the attention of the viewer. Page static and dynamic binding, coordinated, both with the traditional design aesthetic rules of communication, but also to achieve the best condition to convey information.

Web design is the traditional design of inheritance and by extension, with the traditional design forms and manifestations on the object has some similarities, but web design integrates traditional art and design in the form of law, based on the increase of dynamic design elements that make content more dynamic design, more attractive to the viewer's eye. However, these design elements dynamic handling, but also a degree of certainty, with the static off move, this will move the page even more attracting and coordinated the entire page.

\section{Conclusion}

With the development of network technology, on the surface, the web design is techniques and methods on the page layout but in fact, it is not only a skill, but also a high degree of unity of art and technology. Therefore, in the web design process, designers should take the initiative, and flexible use of the formal beauty of the rules, in order to improve the aesthetics of the page and to enhance the quality of the site.

\section{Acknowledgements}

Fund Project: Jiangxi Arts and Sciences Planning Project (YG2015189, YG2014255), 2015 Annual Jiangxi Province College Humanities and Social Science Research Projects (TQ1516), 2015 Annual Pingxiang City Science and Technology Support Program (Research and Development on the Central Region Animation Rendering Service Platform Based on the Cloud Computing).

\section{References}

[1] Jia Xinzhang, Li Jingyuan. Decoration, Vol. 6 (2014) No 53, p.25-26

[2] Peng Sue, Wang Yunhui, Wang Qunyong. Grand Art, Vol. 12 (2015) No 27, p.74-76

[3] Qian Xiyuan, Jing Jianfen. Art Watch, Vol. 30 (2014) No 19, p.144-145

[4] Wang Kuailiang. Literary Criticism, Vol. 29 (2008) No 27, p.21-23

[5] Zhang Gongxu, Sun Jing. Economy Forum, Vol. 8 (2013) No 27, p.57-60 